\title{
Newcastle disease virus-induced autophagy mediates antiapoptotic signaling responses in vitro and in vivo
}

\author{
Yinfeng Kang ${ }^{1,2,3, *}$, Runyu Yuan ${ }^{1,3,4, *}$, Bin Xiang ${ }^{1,3}$, Xiaqiong Zhao ${ }^{1,3}$, Pei Gao ${ }^{1,3}$, Xu Dai ${ }^{1,3}$, \\ Ming Liao ${ }^{1,3}$ and Tao Ren ${ }^{1,3}$ \\ ${ }^{1}$ College of Veterinary Medicine, Key Laboratory of Zoonosis Prevention and Control of Guangdong Province, South China \\ Agricultural University, Guangzhou, 510642, China \\ ${ }^{2}$ State Key Laboratory of Oncology in South China, Collaborative Innovation Center for Cancer Medicine, Department of \\ Experimental Research, Sun Yat-sen University Cancer Center, Guangzhou, 510060, China \\ ${ }^{3}$ Key Laboratory of Animal Vaccine Development, Ministry of Agriculture, Guangzhou, 510642, China \\ ${ }^{4}$ Key Laboratory for Repository and Application of Pathogenic Microbiology, Research Center for Pathogens Detection \\ Technology of Emerging Infectious Diseases, Guangdong Provincial Center for Disease Control and Prevention, Guangzhou, \\ 511430, China \\ *These authors contributed equally to this work \\ Correspondence to: Yinfeng Kang, email: kangyf@sysucc.org.cn \\ Tao Ren, email: rentao6868@126.com
}

Keywords: Newcastle disease virus, autophagy, apoptosis, relationship, replication

Received: February 09, 2017 Accepted: May 12, $2017 \quad$ Published: May 25, 2017

Copyright: Kang et al. This is an open-access article distributed under the terms of the Creative Commons Attribution License 3.0 (CC BY 3.0), which permits unrestricted use, distribution, and reproduction in any medium, provided the original author and source are credited.

\section{ABSTRACT}

In this study, we investigated the role of autophagy and apoptosis in Newcastle disease virus (NDV)-infected chicken cells and tissues. NDV-infected and starvationinduced chick embryo fibroblasts (CEF) cells showed higher autophagosome formation than mock-infected CEF cells on transmission electron microscopy. The NDV-infected CEF cells showed enhanced conversion of microtubule-associated protein 1 light chain 3-I (LC3-I) to LC3-II and degradation of p62/SQSTM1. The diminished conversion of LC3-I to LC3-II and cleaved caspase 3 and poly (ADP-ribose) polymerase (PARP) in ultraviolet-inactivated NDV-infected cells suggested that autophagosome formation was necessary for NDV replication. Inhibition of autophagy by chloroquine (CQ) enhanced apoptosis resulting in increased cleavage of caspase 3 and PARP and AnnexinV/propidium iodide staining. Autophagy induction by rapamycin resulted in upregulation of all autophagy-related genes except Beclin 1, anti-apoptosis factors, and proinflammatory cytokines in the NDV-infected spleen and lung tissues. Subsequently, decreased apoptosis was observed in NDV-infected spleens and lungs than mock-infected organs. The pan-caspase inhibitor ZVAD-FMK promoted conversion of LC3-I to LC3-II, the degradation of P62/SQSTM1, NDV replication and cell viability by inhibiting apoptosis. Our study demonstrates that apoptosis inhibition enhances autophagy and promoted cell survival and NDV replication.

\section{INTRODUCTION}

Newcastle disease virus (NDV), the causative agent of Newcastle disease (ND), is an enveloped, singlestranded, non-segmented, negative-sense RNA virus of the Paramyxoviridae family that causes enormous economic losses to various avian industries worldwide [1]. The
NDV genome is approximately $15 \mathrm{~kb}$ long that encodes six structural proteins, fusion protein $(\mathrm{F})$, hemagglutininneuraminidase protein $(\mathrm{HN})$, nucleocapsid protein $(\mathrm{NP})$, matrix protein $(\mathrm{M})$, phosphoprotein $(\mathrm{P})$, and large polymerase protein $(\mathrm{L})$ and two non-structural proteins, $\mathrm{V}$ and $\mathrm{W}$, which are produced by RNA editing during $\mathrm{P}$ gene transcription as part of the viral life cycle [2]. Although 
compulsive culling and vaccination strategies have greatly reduced the NDV outbreaks, it continues to pose significant health problems to world's avian industries [3].

Cell death in multicellular organisms is classified into apoptosis, autophagy, and necrosis, each of which are morphologically distinct [4]. Apoptosis is a physiologically programmed cell death that is essential for eliminating infected or damaged cells in order to maintain cellular homeostasis and limit disease pathogenesis $[5,6]$. The cell morphological features and biochemical characteristics of apoptosis include DNA fragmentation, cytoplasmic vacuoles, membrane blebbing and formation of apoptotic bodies [6, 7]. Apoptosis can be triggered either intrinsically via mitochondrial outer membrane permeabilization or extrinsically via death receptor oligomerization $[8,9]$. In both cases, the cysteine aspartyl-specific proteases or caspases (e.g., caspase-3, -8 , and -9 ) are activated that trigger morphological and biochemical changes that are characteristic of apoptosis. However, the mechanisms of caspase activation remain distinct. Apoptosis is the first line of cellular defense against pathogen infection that severely attenuates viral proliferation by activation of intracellular stress pathways, thereby resulting in cell death $[10,11]$. Several viruses like the influenza virus, simian virus 40 , herpes simplex virus type 1, human papillomaviruses, and human adenoviruses strategically delay or evade early-stage apoptosis, thereby prolonging the life of the infected cells, thereby helping viral replication [12].

In contrast, autophagy is a homeostatic biological process in which cytoplasmic components like macromolecules (e.g., viruses, proteins, and bacteria) and organelles (e.g., endoplasmic reticulum, golgi apparatus, and mitochondria), are degraded by proteasomes or recycled in lysosomes [13]. The autophagy processes degrade damaged cell components, invading microorganisms and disused or defunct organelles, and also mediate inflammation and immune responses $[13,14]$. Although autophagy is triggered by cellular stress (e.g., starvation, hypoxia, and pathogenic stimuli), the mechanisms of autophagy-mediated innate and acquired immunity are not well characterized. Autophagy plays a crucial role in host defense responses and is critical for cell survival, T cell priming, the production of type I interferons, and major histocompatibility complex (MHC) I or II antigen presentation to CD4+ cells. Many viruses exploit the autophagic processes for replication, survival, and dissemination in host infected cells. For example, the influenza A virus M2 and the dengue virus NS1 proteins inhibit the fusion of autophagosomes and lysosomes $[15,16]$; the human immunodeficiency virus encodes the Nef protein that inhibits the acidification of autophagosomes [17]; and the hepatitis C virus, which expresses the NS4B protein, forms a complex with Rab5 and Vps34 to inhibit the formation of autophagosomes [18].

Although previous studies have demonstrated that NDV infection induces apoptosis and autophagy [19-23], their role during NDV infection is unknown. Therefore, the objective of our study was to investigate the roles of apoptosis and autophagy during NDV infection.

\section{RESULTS}

\section{Newcastle disease virus induces autophagosomes in chicken cells}

The autophagic vacuoles (autophagosomes) is a hallmark feature of autophagy [14, 24]. First, we infected CEF and DF-1 cells with NDV at an MOI of 1 and analyzed autophagosome formation at 12 and $24 \mathrm{~h}$ using TEM. CEF and DF-1 cultures without viral incubation were used as negative controls, whereas EBSS treated CEF and DF-1 cultures were used as positive controls. As shown in Figure 1, we observed increased single- and double-membrane bound structures in NDV and EBSS
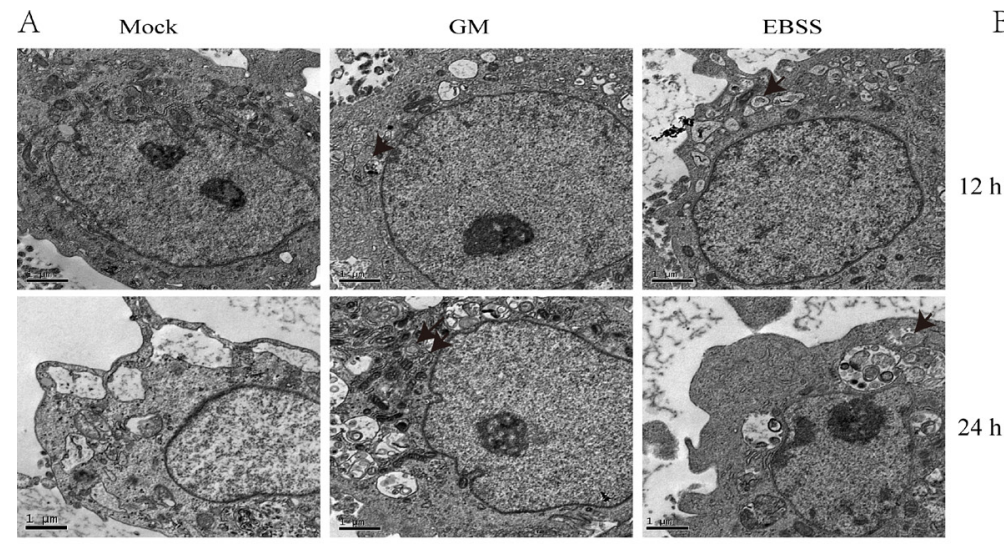

B

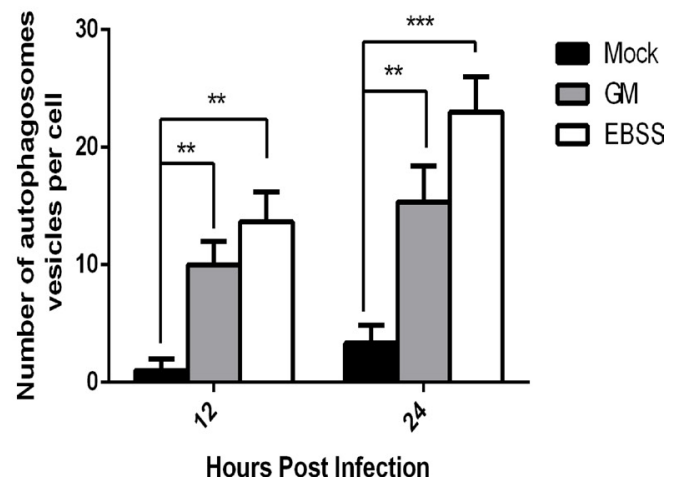

Figure 1: Autophagosome formation in Newcastle disease virus (NDV) chick embryo fibroblast (CEF) cells. (A) CEF cells were infected with NDV at a multiplicity of infection of 1 or treated with EBSS (i.e., starvation) for $1 \mathrm{~h}$ and subjected to transmission electron microscopy at 12 and $24 \mathrm{~h}$ post-infection to observe autophagosomes (indicated by black arrows). (B) Autophagosomes per cell from (A) were calculated; data represent Mean $\pm S D$ for triplicate samples of at least 100 cells per sample. Similar results were obtained from three independent experiments; $* * p<.01, * * * p<.001$ ( $t$ test $)$. 
treated CEF cells at 12 and $24 \mathrm{~h}$ compared to negative controls. Similar results were observed in DF-1 cells (data not shown).

Autophagy is mediated by ATG proteins such as microtubule-associated protein 1 light chain 3 (LC3) that play distinct roles in different stages of autophagosome formation [25]. Therefore, we analyzed LC3 and p62/ SQSTM1 to verify the status of autophagy. CEF cells were infected with NDV at an MOI of 1 and analyzed at $6,12,24$, and $36 \mathrm{~h}$ by western blot to detect conversion of LC3 and the degradation of p62/SQSTM1. As shown in Figure 2A, the conversion of LC3-I to LC3-II induced by NDV was greater than in mock-infected cells, especially at the later stages of infection. Also, NDV infection increased the degradation of p62/SQSTM1 in CEF cells over time (Figure 2B). Similar results were obtained for NDV-infected DF-1 cells (data not presented). These data suggested that NDV strain GM induced autophagy in chicken cells.

\section{Inhibition of autophagy results in apoptosis}

Chloroquine (CQ) is an inhibitor of autophagy by reducing the acidity of lysosomes and inhibiting the fusion of autophagosomes and lysosomes [26]. To elucidate the role of autophagy in NDV-infected chicken cells, CEF cells were pretreated with $50 \mu \mathrm{M}$ CQ for $1 \mathrm{~h}$, infected with NDV $(\mathrm{MOI}=1)$, and analyzed at indicated time points by western blot. The cell culture supernatants were also harvested to detect viral titers by plaque assay at 24 and 48h. As previous studies had shown [20], CQ increased the conversion of LC3-I to LC3-II in CEF cells, but decreased viral yield (Figure 3A and 3B). Moreover, the inhibition of autophagy increased the cleavage of key apoptotic

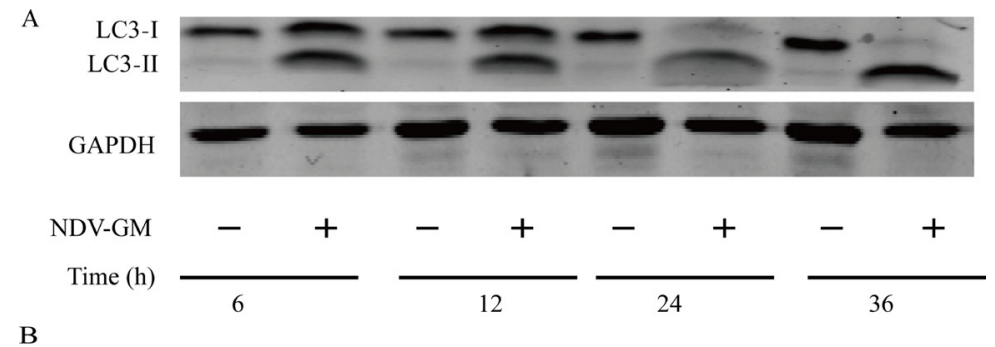

B

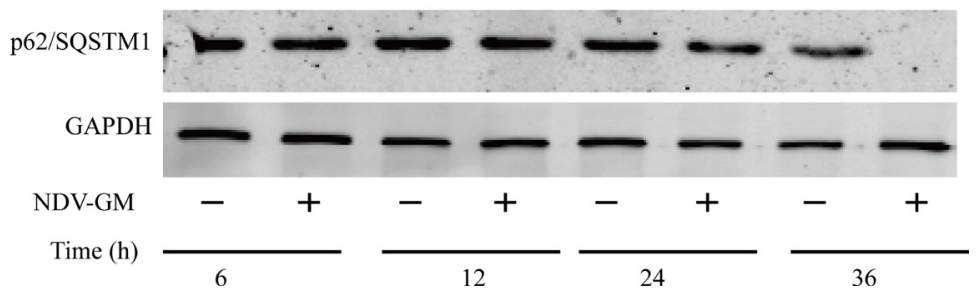

Figure 2: Newcastle disease virus (NDV) infection induces the formation of LC3 puncta (A) and preserves autophagic flux (B) in chick embryo fibroblast (CEF) cells. CEF cells were infected with NDV at a multiplicity of infection of 1 and western blot analysis was performed with anti-LC3B and anti-p62/SQSTM1 antibodies at 6, 12, 24 and $36 \mathrm{~h}$ post-infection. Anti-GAPDH antibody was used as an endogenous control for protein loading.
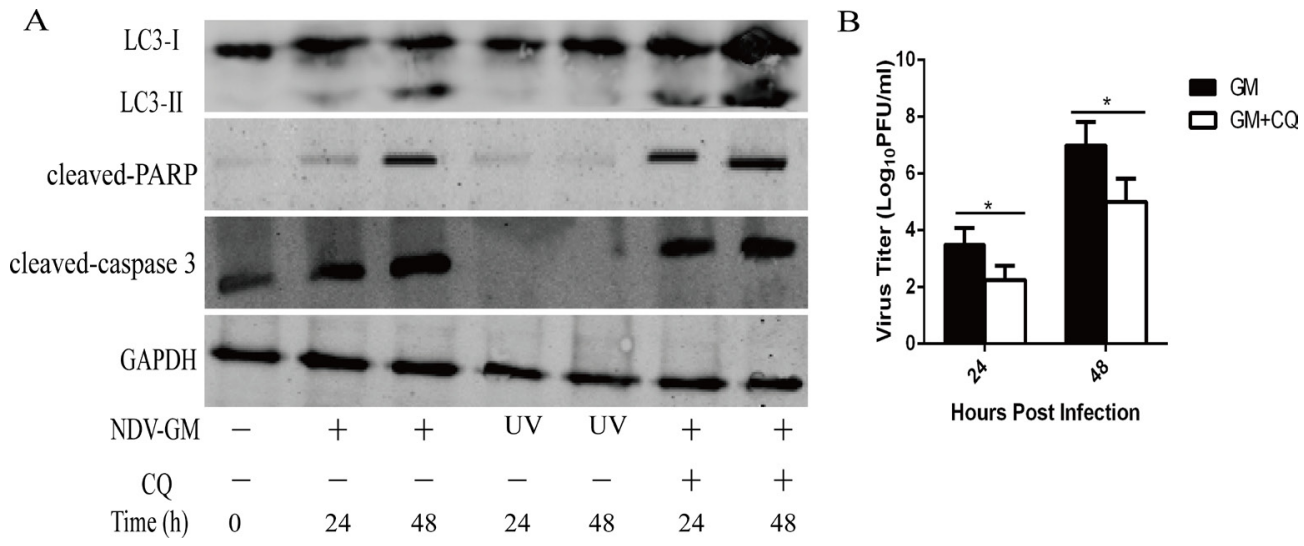

Figure 3: Effect of chloroquine (CQ) on autophagy, apoptosis and NDV replication in NDV-infected CEF cells. (A) CEF cells were preincubated with $50 \mu \mathrm{M}$ CQ for $1 \mathrm{~h}$ followed by infection with NDV at a multiplicity of infection of 1 , after which cell lysates and culture supernatant were harvested for western blot analysis and (B) viral titration by plaque assay at 24 and $48 \mathrm{~h}$ postinfection, respectively. Mock-infected and UV-inactivated NDV-infected CEF cells were used as controls. 
proteins, caspase 3 and PARP at 24 and $48 \mathrm{~h}$ (Figure 3A). Furthermore, CEF cells infected with uv-inactivated NDV, which inhibits virus replication without affecting the interaction of NDV and its receptors (e.g., sialic acid receptor), inhibited conversion of LC3-I to LC3-II and the cleavage of caspase 3 or PARP at 24 and 48 h (Figure 3A). To further confirm that the inhibition of autophagy by CQ promoted NDV-activated apoptosis in CEF cells, we analyzed CEF cells that were pretreated with CQ $(50 \mu \mathrm{M})$ prior to viral infection with NDV $(\mathrm{MOI}=1)$ by annexin $\mathrm{V}$-FITC/propidium iodide double-staining flow cytometry assay at 24 and $48 \mathrm{~h}$. We observed that NDV-infected CEF cells with CQ (20.6 to 33\%) showed increased apoptosis compared to NDV-infected CEF cells without CQ (12.5 to $26 \%$ ) at 24 to 48 h (Figure 4). Therefore, our results demonstrated that autophagy inhibition enhanced apoptosis in NDV-infected chicken cells.

\section{Beclin 1 knockdown enhances apoptosis and decreases viral progeny yield}

Beclin 1, the mammalian orthologue of yeast Atg6, plays a crucial role in autophagy and programmed cell death in mammalian systems $[27,28]$. We investigated the role of autophagy in apoptosis and NDV replication by downregulating Beclin 1 by RNAi. RNAi of Beclin 1 resulted in decreased conversion of LC3-I to LC3-II, Beclin 1 and the viral titers, but increased the cleavage of PARP and caspase 3 at 24 and $48 \mathrm{~h}$ compared to scrambled control siRNAs. These data demonstrated

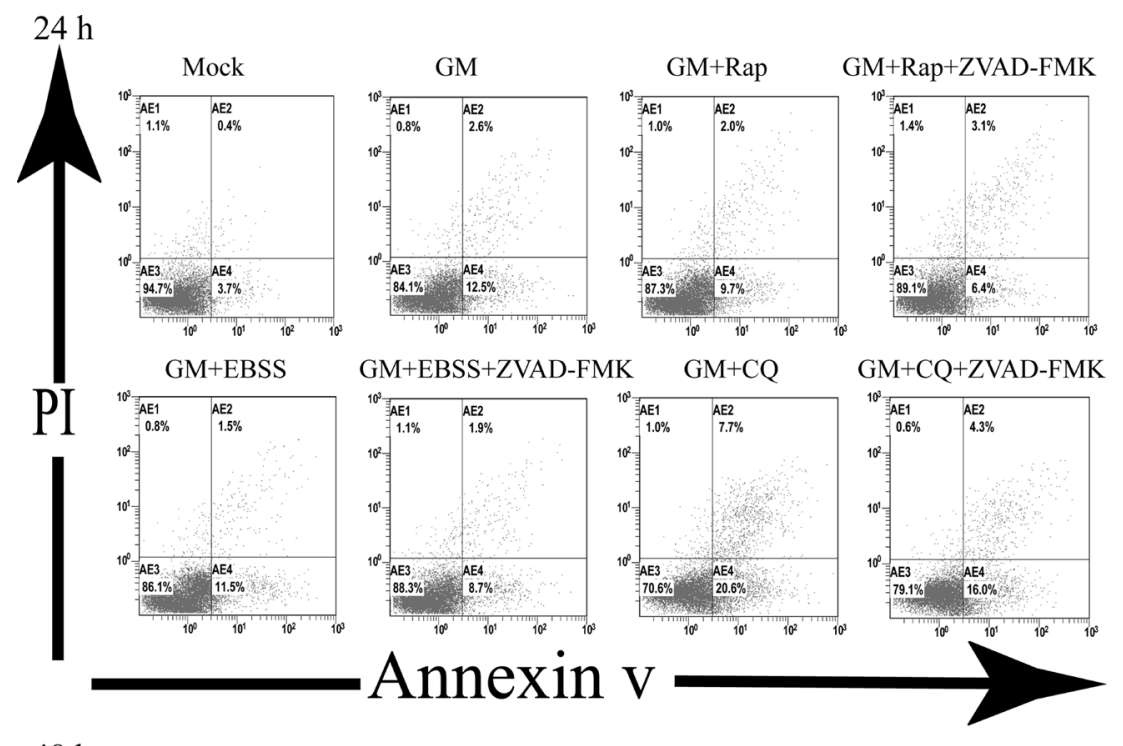

$48 \mathrm{~h}$

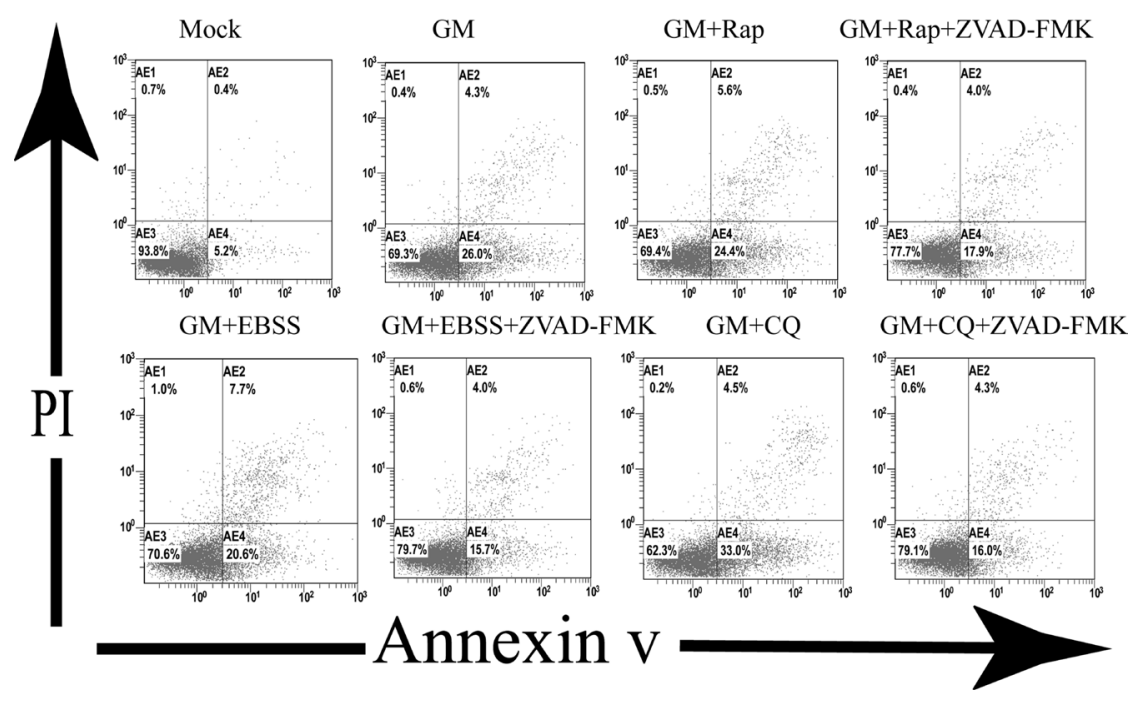

Figure 4: Autophagy regulates apoptosis in NDV-infected CEF cells. CEF cells were pretreated with chloroquine (50 $\mu \mathrm{M})$, rapamycin $(100 \mu \mathrm{M})$, or Earle's Balanced Salt Solution (starvation) in the presence or absence of pan-caspase inhibitor ZVAD-FMK $(40 \mu \mathrm{M})$. Then, the cells were infected with NDV at a MOI of 1 and harvested and stained with annexinV and propidium iodide (PI) at indicated times. Stained cells were analyzed by flow cytometry. AnnexinV-positive and PI-negative cells in the lower right quadrant were counted as apoptotic cells. 
that Beclin 1 was required for autophagy and NDV replication, whereas basal Beclin 1 levels were sufficient to initiate apoptosis.

\section{Induction of autophagy reduces apoptosis}

To further define the relationship between autophagy and apoptosis, CEF cells were pretreated with rapamycin (Rap), an inhibitor of mTORC1 that prevents the accumulation of autophagosomes and induces autophagy; and EBSS, which induces autophagy by nutrient starvation [14]. CEF cells were pretreated with $100 \mu \mathrm{M}$ Rap or EBSS prior to viral infection with NDV at an MOI of 1 . At 24 and 48 hpi, cells were harvested for western blot and flow cytometry analyses, and cell culture supernatants were collected to determine viral titers by plaque assay. As shown in Figure 6A and 6B, Rap treatment increased both the conversion of LC3-I to LC3-II and the NDV viral titers, but decreased the cleavage of PARP and caspase 3. Further, we analyzed apoptosis using annexinV-FITC double-staining flow cytometry assay at 24 and $48 \mathrm{~h}$. We observed decreased apoptosis of NDV-infected CEF cells with Rap treatment compared to NDV-infected CEF cells without Rap (Figure 5). Similar results were obtained with EBSS treatment (Figure 6C and 6D). Overall, our results indicated that the induction of autophagy promoted virus replication but decreased apoptosis in host cells.

\section{Inhibition of apoptosis enhances autophagy and cell survival}

To investigate the role of apoptosis in NDV-induced autophagy and cell survival, we used a pan-caspase inhibitor, ZVAD-FMK that blocks caspase-dependent apoptosis [29]. We preincubated CEF cells with increasing concentrations of ZVAD-FMK $(10,20,30$, and $40 \mu \mathrm{M})$ in the presence or absence of CQ $(50 \mu \mathrm{M})$ and then infected the cells with NDV $(\mathrm{MOI}=1)$. After $24 \mathrm{~h}$, we analyzed cell lysates by western blot. Treatment with CQ $(50 \mu \mathrm{M})$ prior to NDV infection increased the cleavage of PARP and caspase 3 (Figure 7A). However, treatment with ZVAD-FMK prior to NDV infection increased the conversion of LC3-I to LC3-II, the level of the NDV-P protein, and the degradation of p62/SQSTM1, but inhibited the cleavage of PARP and caspase 3 in a dosedependent manner (Figure 7A). Interestingly, incubation with the pan-caspase inhibitor ZVAD-FMK in the presence of $\mathrm{CQ}$ reversed NDV-induced conversion of LC3-I to LC3-II and the degradation of p62/SQSTM1 in a dose-dependent manner. Next, we investigated if pretreatment with ZVAD-FMK reversed apoptosis after exposure to NDV in the presence of autophagy inhibitor or inducers (e.g., CQ, Rap and EBSS). Therefore, CEF cells were pretreated with CQ $(50 \mu \mathrm{M})$, Rap $(100 \mu \mathrm{M})$, or EBSS ( starvation) in the presence of ZVAD-FMK $(40 \mu \mathrm{M})$ for $1 \mathrm{~h}$ prior to NDV infection at an MOI of 1 and stained with annexin-V and PI at 24 and 48 hpi and analyzed by flow cytometry. As shown in Figures 4 and $7 \mathrm{~B}$, incubation with ZVAD-FMK decreased apoptosis in NDV-infected CEF cells without an autophagy inhibitor or inducer alone. Hence, our results indicated that the inhibition of apoptosis decreased apoptosis and enhanced host survival signals in response to NDV infection.

\section{Inhibition of autophagy enhances apoptosis in vivo}

The in vivo relationship between autophagy and apoptosis after NDV infection is not well known. Previous research reported that a goose-source NDV strain, Herts/33 (genotype II) induced autophagy in vivo and in vitro; CQ treatment inhibited virus replication in $7 \mathrm{~d}$ old SPF chicken lung tissues but did not increase chicken survival rates; and treatment with Rap promoted virus replication in $7 \mathrm{~d}$ old SPF chicken lung tissues without affecting survival rates [20]. Therefore, we investigated the in vivo role of autophagy in NDV replication and
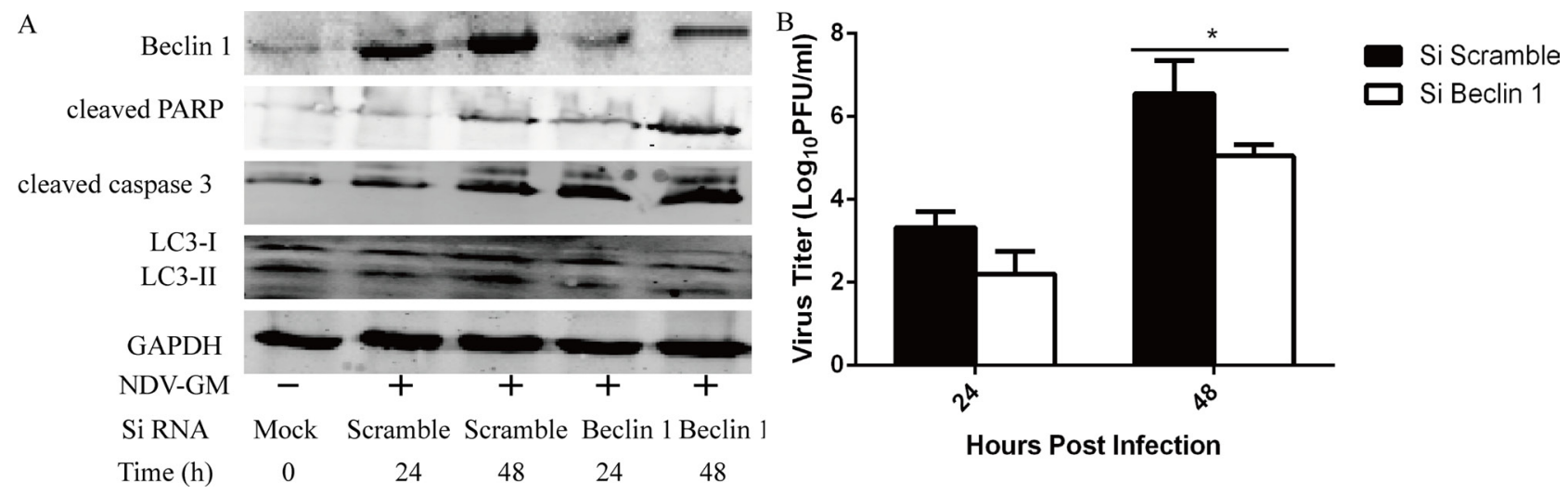

Figure 5: Inhibition of autophagy by Beclin1 knockdown enhances apoptosis but reduces NDV replication in CEF cells. CEF cells were transfected with Beclin1-specific or control scrambled siRNAs for $24 \mathrm{~h}$ followed by NDV infection at a MOI of 1 . Cell lysates and culture supernatant were harvested and subjected to western blot analysis (A) and viral titration by plaque assay (B) at 24 and $48 \mathrm{~h}$ post-infection, respectively. Mean $\pm S D$ of three independent experiments are shown; ${ }^{*} p<.05$ ( $t$ test). 
A

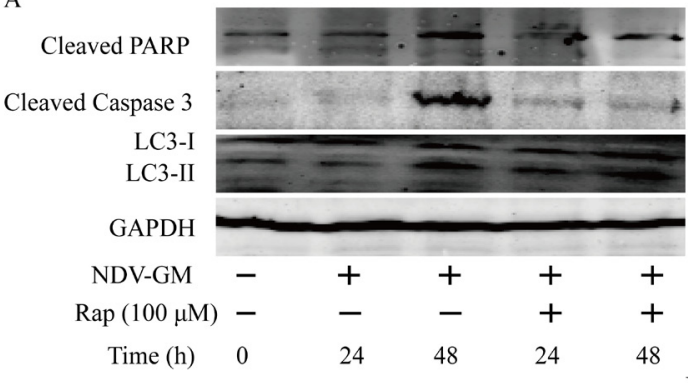

$\mathrm{C}$

Cleaved PARP

Cleaved Caspase 3

$$
\begin{array}{r}
\text { LC3-I } \\
\text { LC3-II }
\end{array}
$$

GAPDH

NDV-GM

EBSS

Time (h)

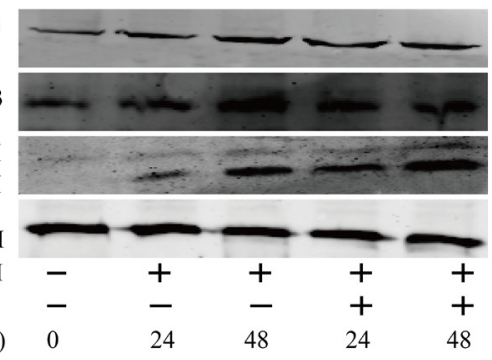

$\mathrm{B}$
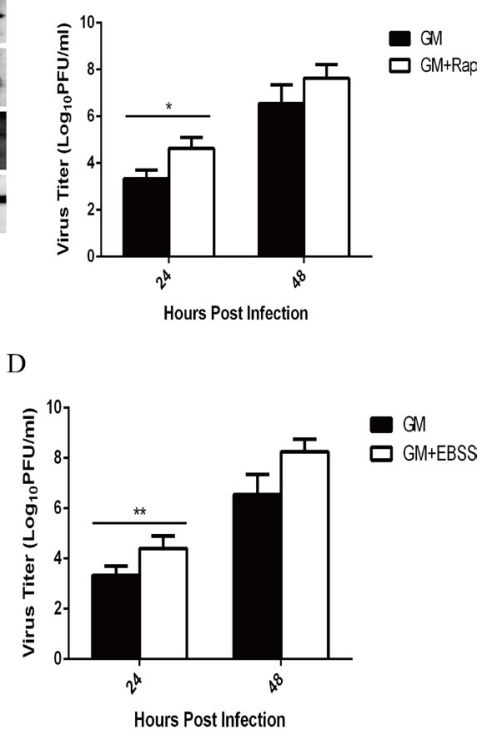

Figure 6: Induction of autophagy by rapamycin (Rap) or Earle's balanced salt solution (EBSS) blocks apoptosis but promotes NDV replication in CEF cells. CEF cells were pretreated with Rap $(100 \mu \mathrm{M})$ or EBSS ( starvation) for 1h followed by infection with NDV at a MOI of 1. Cell lysates and culture supernatants were harvested and subjected to western blot analysis $(\mathbf{A}$ and $\mathbf{C})$ and viral titration by plaque assay (B and $\mathbf{D})$ at 24 and $48 \mathrm{~h}$ post-infection, respectively. Mean $\pm S D$ of three independent experiments are shown; ${ }^{*} p<.05, * * p<.01$ ( $t$ test).

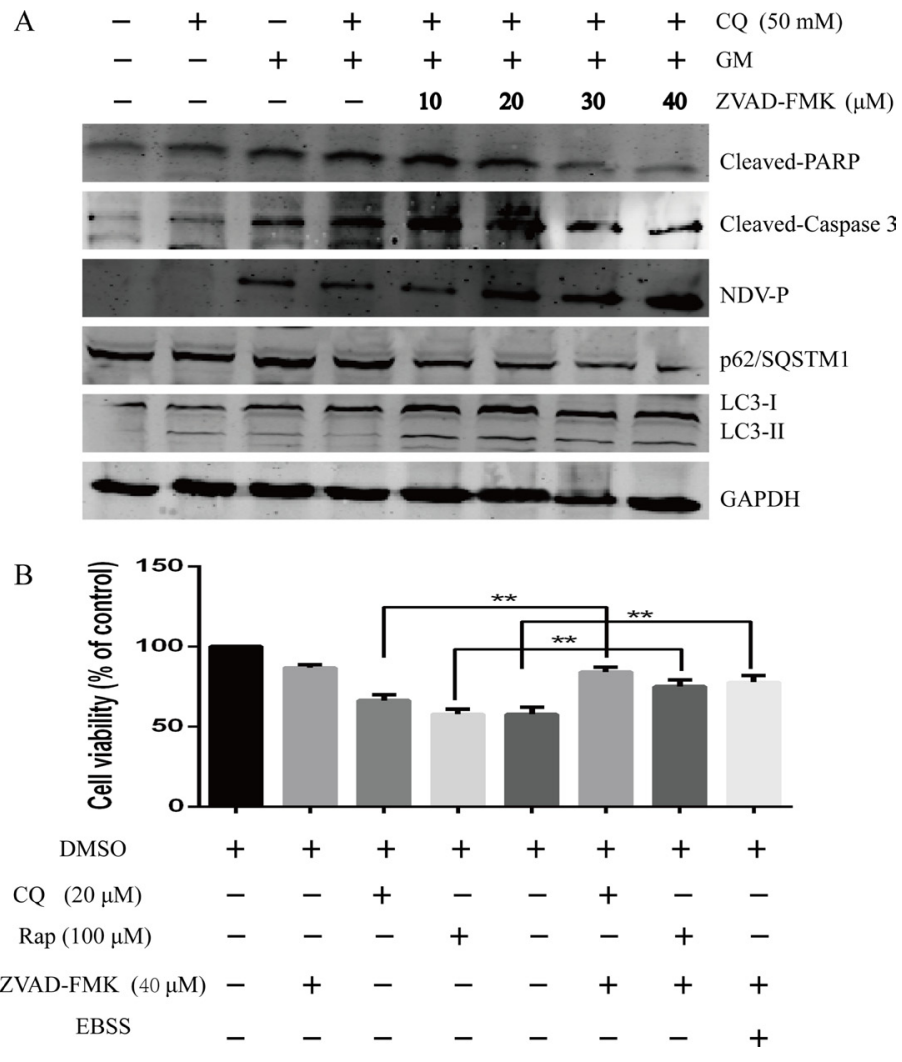

Figure 7: Inhibition of apoptosis precedes the enhanced induction of autophagy and the NDV-stimulated survival pathway. (A) CEF cells were pretreated with increasing concentrations of ZVAD-FMK $(10,20,30$, and $40 \mu \mathrm{M})$ in the presence or absence of chloroquine (CQ, $50 \mu \mathrm{M})$, followed by NDV infection at a MOI of 1 for $1 \mathrm{~h}$. At $24 \mathrm{~h}$ post-infection, cell lysates were subjected to western blot analysis. (B) CEF cells were incubated with Z-VAD-FMK $(40 \mu \mathrm{M})$ in the presence of dimethyl sulfoxide with or without CQ $(50 \mu \mathrm{M})$, rapamycin $(100 \mu \mathrm{M})$, or Earle's Balanced Salt Solution (starvation) for $24 \mathrm{~h}$. Cell viability was determined by methylthiazolyldiphenyltetrazolium bromide (MTT) assay. Mean $\pm S D$ of three independent experiments are shown; ${ }^{* *} p<.01$ ( $t$ test). 
apoptosis in 1d old SPF chickens. We observed that pretreating chickens with Rap accelerated the time of death during the $14 \mathrm{~d}$ experimental period compared to NDVinfected chickens alone (Figure 8A, 8B). The viral titers of lung, brain, thymus, and oropharyngeal swab samples after exposure to Rap were higher than NDV-infected chickens alone at $3 \mathrm{dpi}$. In contrast, pretreating chickens with CQ increased survival rates (75\%) during the $14 \mathrm{~d}$ observation period. CQ treatment also reduced the viral titers of the spleen, lung, thymus, and brain tissues, as well as the oropharyngeal and cloacal swab samples compared to NDV-infected chickens alone at 3 dpi.

To further investigate the role of autophagy in apoptosis in vivo, we harvested the lung and spleen tissues for flow cytometry analysis. As shown in Figure 9, treatment with Rap decreased the percentage of apoptotic cells, whereas treatment with CQ increased the percentage of apoptotic cells in the lung and spleen compared to infection with NDV alone. Further, we examined the levels of the autophagosome initiation complex (ULK1, UVRAG, Beclin 1, and ATG14), the autophagosome elongation complex (ATG3, ATG4A, ATG4B, ATG12, and $A T G 16 L)$, and the autophagosome maturation complex ( $L C 3 B, L C 3 A, G A B A R A P, A T G 5$, and $A T G 7)$, as well as the apoptosis-related genes B-cell lymphoma extra large (Bcl-xL), B-cell lymphoma 2 ( $B c l-2)$, apoptotic protease activating factor 1 (Apaf-1), and caspase 3, in addition to the proinflammatory cytokines interleukin 6 (ILO) and interleukin $1 \beta(I L-1 \beta)$ in the lung and spleen tissues following infection with NDV. We observed that $U V R A G$, ATG14, ATG3, ATG4A, ATG4B, ATG12, ATG16L, LC3A, $L C 3 B, G A B A R A P, A T G 5$, and $A T G 7$, of anti-apoptotic
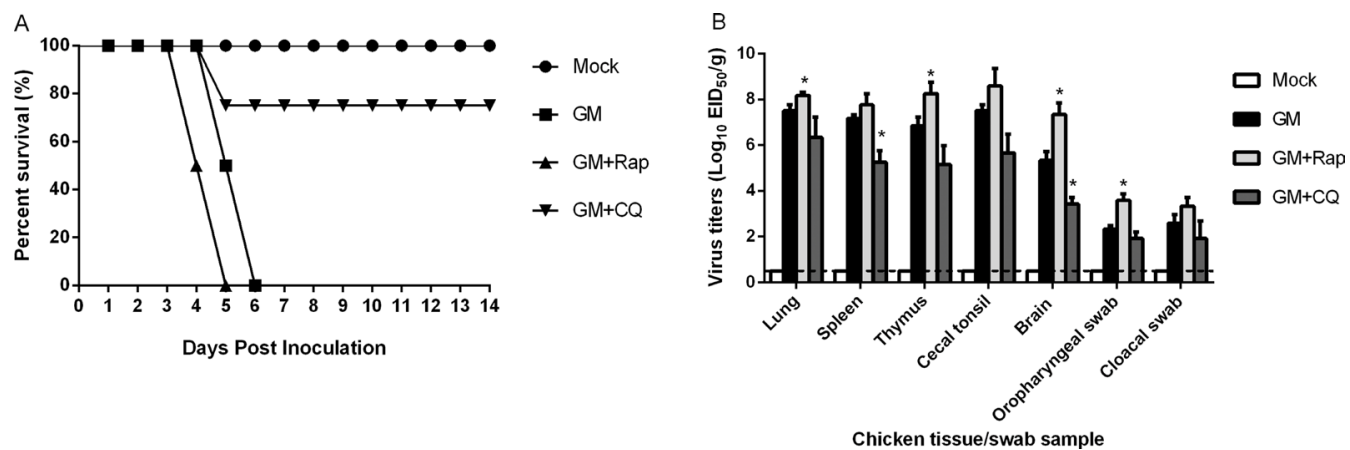

Figure 8: In vivo analysis of rapamycin (Rap), chloroquine (CQ) and mock-treated chicken groups infected with NDV. Thirty-two 1d old SPF chicken were randomly divided into four groups and treated intracerebrally with CQ (40 mg/kg), Rap (2 mg/kg), or an equal volume of phosphate-buffered saline (PBS) $1 \mathrm{~h}$ before the administration of NDV and further at 12, 24, 36 and $48 \mathrm{~h}$ post-infection. Chicken were inoculated with $200 \mu \mathrm{L}$ of $10^{3} 50 \%$ egg infectious dose $\left(\mathrm{EID}_{50}\right)$ of the virus intranasally or intraocularly. Mock-infected chickens were injected intracerebrally with the same volume of PBS as a negative control. (A) The percent survival curve of chicken pretreated with CQ or Rap followed by NDV infection. (B) Virus titers in chicken tissues and swabs. At 3d post-infection, four chicken of each group were euthanized, and lung, spleen, brain, cecal tonsil, and thymus tissue, as well as oropharyngeal and cloacal swab samples were harvested and titrated for virus infectivity in SPF-embryonated chicken eggs.

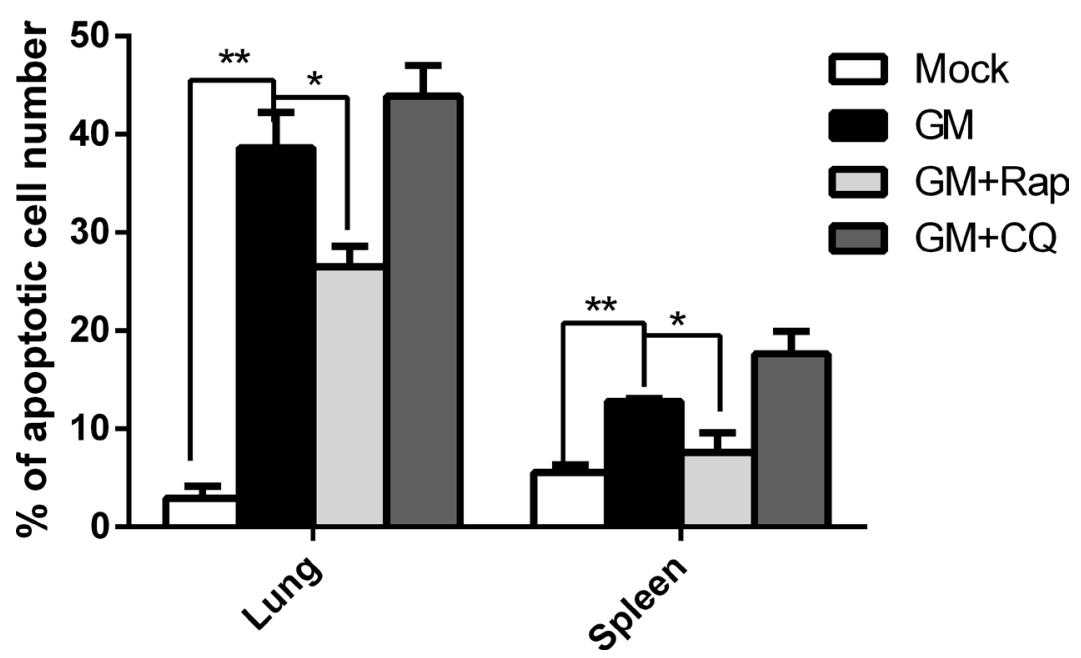

Figure 9: Regulation of autophagy affects apoptosis in vivo. Chicken were pretreated with chloroquine or rapamycin as described in the materials and methods followed by NDV infection, after which lung and spleen tissues were harvested and ground for flow cytometry analysis using an AnnexinV-FITC/propidium iodide double-staining apoptosis detection kit. Mean $\pm S D$ of three independent experiments are shown. Similar results were observed in three independent experiments; ${ }^{*} p<.05,{ }^{* *} p<.01(t$ test $)$. 
genes (i.e., $B c l-x L$ and $B c l-2$ ), and of proinflammatory cytokines (i.e., $I L-6$ and $I L-1 \beta$ ) were upregulated in NDVinfected spleen and lung tissue compared to mock-infected chickens (Figure 10). However, ULK1, Beclin 1, and caspase 3 were downregulated in the NDV-infected spleen, thereby suggesting that the spleen resisted the formation of autophagosomes. Furthermore, treatment with Rap increased $A T G, B c l-x L, B c l-2$, caspase 3, $I L-6$, and $I L-1 \beta$ in the spleen and lung. However, $L C 3 A$ and Apaf-1 in the spleen and Beclin 1, LC $3 A, L C 3 B$, and Apaf-1 in the lung were similar in Rap treated and NDV-infected only chickens. However, treatment with CQ downregulated $A T G, B c l-x L, B c l-2, I L-6$, and $I L-1 \beta$, but not Apaf- 1 in the spleen and lung compared to NDV-infected only chickens. Therefore, our results demonstrated that autophagy was essential for in vivo NDV replication and apoptosis.

\section{DISCUSSION}

Autophagy is a highly dynamic catabolic process involving degradation or recycling of cytoplasmic proteins and damaged organelles to maintain cellular homeostasis [25]. Autophagy is exploited by many viruses, including hepatitis C [30], influenza A [31, 32], dengue [33], classical swine fever [34], and NDV [20-22] to provide a physical scaffold for virus replication. Although previous studies have demonstrated that autophagy and apoptosis are both induced by NDV infection $[19,20]$, their interplay is not fully understood. In our study, we used the predominant genotype VII NDV strain (GM) in southern China to investigate the role of autophagy in NDV infection in chicken cells and tissues [3] and the relationship between autophagy and apoptosis.

The caspase family of proteins, including caspase 3 and PARP are involved in mediating the death-receptor and mitochondria-cytochrome pathways of apoptosis in host cells $[6,7,9]$. As reported previously for porcine reproductive and respiratory syndrome virus $[35,36]$, chikungunya virus [37], and enterovirus 71 [38], NDV triggers autophagy in chicken cells and inhibits caspasedependent apoptosis as demonstrated by diminished cleavage of caspase 3 and PARP coinciding with autophagy induction by Rap and EBSS (Figure 6A and 6B). Also, the broad-specificity caspase inhibitor ZVAD-FMK inhibits
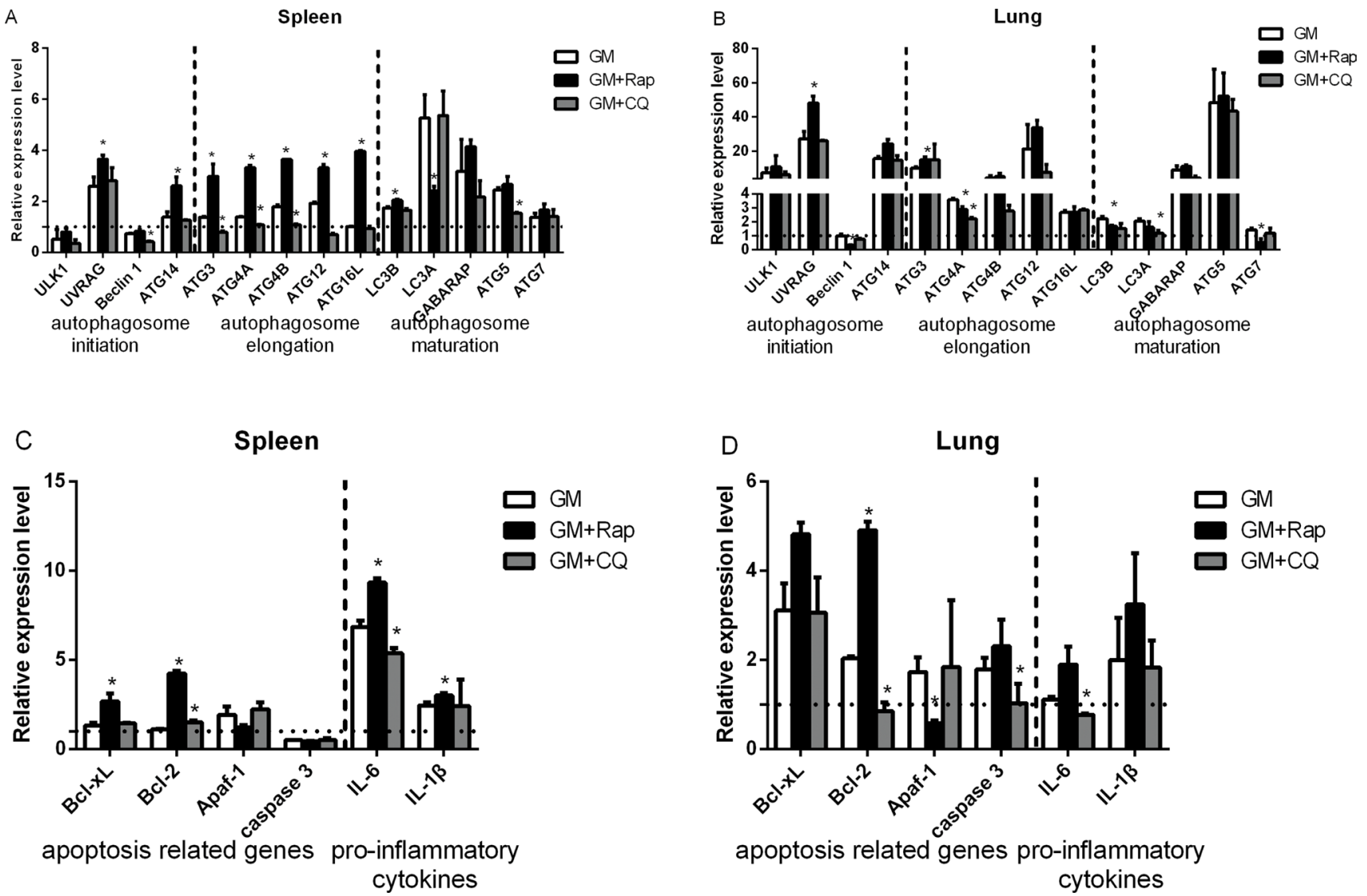

Figure 10: Relative expression of autophagy and apoptosis related genes, and proinflammatory cytokines in NDVinfected chicken spleens and lungs. Chicken were pretreated with chloroquine or rapamycin as described in materials and methods followed by NDV infection, after which lung and spleen tissue was harvested and ground. Total RNA in the lung and spleen were extracted, reverse transcribed, and subjected to qRT-PCR to measure autophagy-related genes (A and B), apoptosis-related genes, and pro-inflammatory cytokines $(\mathbf{C}$ and $\mathbf{D})$. Mean $\pm S D$ of three independent experiments are shown. Similar results were observed in three independent experiments; ${ }^{*} p<.05(t$ test). 
cytokine activation and apoptosis initiation and execution in host cells [29]. It also reversed pro-apoptotic signals like conversion of LC3-I to LC3-II and degradation of p62/ SQSTM1 and reduced apoptosis consistent with previous studies [37, 39]. Our results, therefore indicate that both autophagy and apoptosis are triggered by NDV infection in a caspase-dependent manner.

The induction of autophagy triggered by various viruses inhibits apoptosis and promotes virus propagation by prolonging the lifespan of host infected cells [40]. Our findings demonstrated that the inhibition of autophagy by CQ or the knockdown of Beclin 1 results in enhanced apoptosis as demonstrated by cleavage of caspase 3 and PARP, but also reduces viral titers in CEF cells (Figures 3 and 5). Likewise, in vivo treatment with $\mathrm{CQ}$ improves the survival rate of chicken by decreasing virus replication and shedding (Figure 8). These data indicate that the inhibition of autophagy promotes apoptosis as described for herpes simplex virus 1 and mouse herpesvirus 68 [41]. However, we could not demonstrate exclusive roles of autophagy and apoptosis in response to NDV infection.

The process of autophagy in mammalian cells involves six principal steps: initiation, nucleation, elongation, closure, maturation, and degradation [27]. We examined the mRNA levels of components of the autophagosome initiation complex (ULK1, UVRAG, Beclin 1, and ATG14), the autophagosome elongation complex (ATG3, ATG4A, ATG4B, ATG12, and ATG16L), and the autophagosome maturation complex ( $L C 3 B$, $L C 3 A, G A B A R A P, A T G 5$, and ATG7) in the lung and spleen following NDV infection. We observed that the expression levels of all $A T G$ proteins except $U L K 1$ in the spleen and Beclin 1 in the lung were upregulated when autophagy was induced by Rap (Figure 10). This suggested that autophagy was related to the chicken immune system or gender-specific differences, if not both $[31,42]$. In contrast, the inhibition of autophagy decreased the expression levels of ATG proteins in the tissues targeted by NDV. Taken together, our results indicate that autophagy plays a crucial role in the response to NDV infection in host infected chickens.

In conclusion, we demonstrated that autophagy triggered by genotype VII NDV infection was essential for viral replication, NDV-induced apoptosis, and cell survival in chicken cells and tissues. These findings expand on the current understanding of the pathogenesis of NDV and provide new insights to control and prevent NDV infection.

\section{MATERIALS AND METHODS}

\section{Ethics statement}

Animal experiments were carried out in ABSL-3 facilities and were conducted in accordance with the guidelines of CDC's Institutional Animal Care and Use
Committee. The South China Agricultural University Experimental Animal Welfare Ethics Committee approved this study (permit no. 2015-03).

\section{Cells, virus, and experimental animals}

Chick embryo fibroblasts (CEF) and DF-1 chicken fibroblasts (ATCC CRL-12203) were cultured and maintained in Dulbecco's modified Eagle's medium (DMEM, Life Technologies, Guangzhou, China) supplemented with $10 \%$ fetal bovine serum (FBS, Gibco, Carlsbad, CA, USA) with penicillin (100U/mL) and streptomycin $(0.1 \mathrm{mg} / \mathrm{ml}$, Sigma-Aldrich, Shanghai, China) at $37^{\circ} \mathrm{C}$ in a humidified $5 \% \mathrm{CO}_{2}$ incubator. The NDV strain Chicken/Guangdong/GM/2014 (GM), whose genotype (VII) is predominant worldwide [3], was isolated from dead chicken in China's Guangdong Province and propagated in 9d old specific-pathogen-free (SPF) embryonated chicken eggs. Virus titers were determined by plaque assay as described previously [43, 44]. For in vivo studies, a group of 1d old SPF chicken were purchased from Guangdong Wens Dahuanong Biotechnology Co., Ltd (Yunfu, China) and housed in isolator cages

\section{Chemicals and antibodies}

Rapamycin (Rap, R0395), chloroquine (CQ, PHR1258), rabbit polyclonal antibody of anti-p62/ SQSTM1 (P0067), mouse monoclonal anti-GAPDH antibody (G8795), rabbit polyclonal anti-LC3B antibody (L7543), pan-caspase inhibitor ZVAD-FMK (V116) and annexin V-fluorescein isothiocyanate (FITC) doublestaining apoptosis detection kit were purchased from Sigma-Aldrich. The rabbit polyclonal anti-Beclin 1 antibody (3738), the mouse polyclonal anti-poly(ADPribose) polymerase (PARP) antibody (9542), and the mouse polyclonal caspase-3 antibody (9662) were obtained from Cell Signaling Technology (MA, USA). Earle's Balanced Salt Solution (EBSS,14155063) was purchased from Life Technologies. The mouse polyclonal anti NDV-P antibody was acquired from Key Laboratory of Animal Vaccine Development, Ministry of Agriculture (Guangzhou, China). IRDye 680 goat anti-rabbit IgG and IRDye $800 \mathrm{CW}$ goat anti-mouse IgG were purchased from LI-COR Biosciences (NE, USA). Beclin 1 small interfering RNA (siRNA) and a scrambled siRNA control were designed and synthesized by Life Technologies.

\section{Chemical treatment and virus infection of chicken cells}

CEF and DF-1 cells were pretreated with dimethyl sulfoxide (DMSO), CQ, or Rap for $1 \mathrm{~h}$ and then infected at a multiplicity of infection (MOI) of 1 with NDV, followed by adsorption in a $5 \% \mathrm{CO}_{2}$ incubator at $37^{\circ} \mathrm{C}$ for $1 \mathrm{~h}$. The optimal concentrations of CQ and Rap in our experiments 
were based on earlier research [20]. At indicated time points, cells and culture supernatants were harvested for further studies.

\section{Cell viability assay}

Cell viability was measured by methylthiazolyldiphenyl-tetrazolium bromide (MTT) cell proliferation and cytotoxicity assay (Sigma Aldrich, USA) following the manufacturer's protocol. Data represent average of three independent experiments.

\section{Transmission electron microscopy}

CEF and DF-1 cells were infected with NDV at an MOI of 1 and harvested at 12 and 24h post-infection (hpi). The cells were fixed with $2.5 \%$ glutaraldehyde solution for $30 \mathrm{~min}$ at $4{ }^{\circ} \mathrm{C}$ and post-fixed with $1 \%$ osmium tetroxide in $0.1 \mathrm{M}$ sodium cacodylate buffer for $2 \mathrm{~h}$ at $4^{\circ} \mathrm{C}$. Then, the cells were dehydrated with a graded series of ethanol and embedded in epoxy resin. Ultrathin $(60 \mathrm{~nm})$ sections were obtained, stained with uranyl acetate and lead citrate and observed and photographed under JEM-2010HR TEM. Mock-infected and EBSS-treated cells were used as negative and positive controls, respectively.

\section{Transfection of small interfering RNA}

CEF or DF-1 cells were grown to $80 \%$ confluence in $60 \mathrm{~mm}$ cell culture dishes and transfected with Beclin1-specific or scrambled control siRNAs with Lipofectamine 3000 (Invitrogen, Carlsbad, CA, USA) according to the manufacturer's instructions. Briefly, $1 \mu \mathrm{g}$ of siRNA was diluted in $100 \mu \mathrm{L}$ of reduced serum medium (Opti-MEM, Gibco). Then, $2.5 \mu \mathrm{L}$ of Lipofectamine 3000 was directly pipetted into the diluted siRNA solutions, and gently shaken followed by incubation at room temperature for $20 \mathrm{~min}$. The cell culture media in the $60-\mathrm{mm}$ cell culture dishes were removed and washed thrice with DMEM and then replaced with $4 \mathrm{ml}$ of Opti-MEM containing the siRNA and the transfection reagents and further cultured at $37^{\circ} \mathrm{C}$ and $5 \% \mathrm{CO}_{2}$. After $6 \mathrm{~h}$, the cell culture supernatants were removed, and fresh DMEM containing 10\% FBS was added to the cells for $24 \mathrm{~h}$. Following infection with NDV for $1 \mathrm{~h}$, infected cell lysates and supernatants were harvested for western blot analysis and plaque assay at 24 and $48 \mathrm{hpi}$, respectively.

\section{Western blot analysis}

The cells were lysed in radioimmunoprecipitation assay buffer containing protease inhibitor tablets (Roche, 88266) on ice followed by ultrasonication and centrifugation at $14,000 \times \mathrm{g}$ for $10 \mathrm{~min}$ at $4^{\circ} \mathrm{C}$. The protein concentration of cell lysates was quantified with the bicinchoninic acid protein assay kit (Pierce, 23227).
Equal amounts of protein $(25 \mu \mathrm{g})$ were denatured for 6 min at $95^{\circ} \mathrm{C}$ in $2 \times$ sodium dodecyl sulfate polyacrylamide gel electrophoresis (SDS-PAGE) loading buffer, separated by $15 \%$ or $12 \%$ SDS-PAGE gels, and electrophoretically transferred onto nitrocellulose membrane (Whatman Schleicher \& Schuell, Dassel, Germany) using the semidry blotting method. Then, the blots were blocked for $2 \mathrm{~h}$ at room temperature in Tris-buffered saline containing $0.1 \%$ Tween- 20 and $5 \%$ bovine serum albumin and then incubated with primary antibodies at $4{ }^{\circ} \mathrm{C}$ overnight, followed by incubation with the corresponding IRDye 680-conjugated anti-rabbit IgG or IRDye 800-conjugated anti-mouse $\operatorname{IgG}$ secondary antibodies $(1: 10,000)$ in the dark for $1 \mathrm{~h}$. After the membrane was washed thrice with tris-buffered saline containing $0.1 \%$ Tween-20, the blots were visualized with the Odyssey Infrared Imaging System (LI-COR Biosciences).

\section{Animal experiments}

Thirty-two 1d old SPF chicken were randomly divided into four groups and treated intracerebrally with CQ (40 mg/kg), Rap (2 mg/kg), or an equal volume of PBS for $1 \mathrm{~h}$ before administration of NDV followed by further intracerebral inoculation at 12, 24, 36, and 48 hpi as previously described [20]. Pharmacologically treated chicken were inoculated with $200 \mu \mathrm{l}$ of a $10^{3}$ $50 \%$ egg infectious dose $\left(\mathrm{EID}_{50}\right)$ of the virus intranasally or intraocularly. Mock-infected chicken were injected intracerebrally with the same volume of PBS as negative control. All chicken were observed for morbidity and mortality in $12 \mathrm{~h}$ intervals for $14 \mathrm{dpi}$. At $3 \mathrm{dpi}$, four chicken of each group were euthanized and lung, spleen, brain, cecal tonsil and thymus tissues were harvested and titrated for virus infectivity in SPF-embryonated chicken eggs. Lung and spleen tissues, which are specific targets of NDV infection were ground and subjected to flow cytometry analysis of apoptosis. Also, RNA samples were subjected to qRT-PCR analysis to evaluate the mRNA expression levels of autophagy-related genes (ATG), apoptosis-related genes, and proinflammatory cytokines. Oropharyngeal and cloacal swabs samples were also collected from chickens at $3 \mathrm{dpi}$ and suspended in $1 \mathrm{ml}$ PBS to detect NDV shedding.

\section{Flow cytometry analysis}

Flow cytometry was performed to determine apoptosis using annexinV-FITC double-staining apoptosis detection kit according to the manufacturer's protocol. First, CEF and DF-1 cells were pretreated with CQ, Rap or EBSS for $1 \mathrm{~h}$ and then infected with NDV at an MOI of 1. Chicken were pretreated as described in the animal experiment. For flow cytometry analysis, cells were harvested and washed thrice with phosphate buffer saline (PBS), centrifuged, and suspended in $500 \mu \mathrm{L}$ of 
Table 1: Quantitative reverse transcription-polymerase chain reaction primers used in this study

\begin{tabular}{|c|c|c|c|c|}
\hline Gene & Forward primer $\left(5^{\prime} \rightarrow 3^{\prime}\right)$ & Reverse primer $\left(5^{\prime} \rightarrow 3^{\prime}\right)$ & Product size (bp) & Accession number \\
\hline GAPDH & ССТCTCTGGCAAAGTCCAAG & CATCTGCCCATTTGATGTTG & 200 & NM_204305 \\
\hline ULK1 & CAGCCCATCCCCAGTGATTT & GCATACCGGAGACTCGAAGG & 121 & XM_015275648 \\
\hline UVRAG & TTTAACGCAGCCTGTAGCCA & GGGTATTGGTTAGGCTCCCG & 57 & NM_001030839 \\
\hline LC3A & GAATCCCACCCAGGCTTTCT & GTCTCCTGGGAAGCGTAGAC & 80 & XM_417327 \\
\hline $\mathrm{LC} 3 \mathrm{~B}$ & GTACGAGAGCGAGAAGGACG & AGACGGAAGATTGCACTCCG & 75 & NM_001031461 \\
\hline Beclin 1 & TACGCAGGTCAGCTTTGTGT & ACATCATTCTGGCTGGTGGG & 61 & NM_001006332 \\
\hline ATG7 & TCTGCCAAGTGTCTGTTGCT & CACCCCAACCCATCAGAGTC & 57 & NM_001030592 \\
\hline ATG5 & ATACAGCCCTTCCTTGGAGC & TAACCCCATCCACAGTTGCT & 66 & NM_001006409 \\
\hline ATG14 & GTGCTGACCTGGAAGACTCC & CCAGATCCGTCTCTTCGTCG & 61 & XM_426476 \\
\hline GABARAP & CTGCGAAGGGGAGAAGATCC & CGCTGTAGGCGATGTAGAGG & 93 & KP064313 \\
\hline ATG12 & GCACCCGCACCATCCA & GAGGCCATCAGCTTCAGGAA & 61 & XM_003643073 \\
\hline ATG16L & TGCATCCAGCCAAACCTTTC & CGACGCTGGTGGCTTGTC & 57 & XM_003641751 \\
\hline ATG4A & CACAGCAGTGCACATTTGCA & CAGAGTCCTGCTGCGTTCCT & 62 & NM_001271986 \\
\hline ATG4B & CCCCGATGAAAGCTTCCA & GCTCAGCGATGCTCATTCTG & 56 & NM_213573 \\
\hline ATG3 & GAACGTCATCAACACGGTGAA & TGAGGACGGGAGTGAGGTACTC & 65 & NM_001278070 \\
\hline Bcl-xL & CTCCATATCACCCCTGGCAC & CCCCCAGTTCACACCATCAT & 127 & GU230783 \\
\hline $\mathrm{Bcl}-2$ & GGATGGGATGCCTTTGTGGA & AGAGTGATGCAAGCTCCCAC & 132 & D11382 \\
\hline caspase 3 & AAAGATGGACCACGCTCAGG & TCCGGTATCTCGGTGGAAGT & 96 & NM_204725 \\
\hline Apaf-1 & GCCAAGCTACGGGCTCAAA & CGAACAACCAGACGGGAAAG & 180 & XM_015289686 \\
\hline IL-6 & GAAGGAAGAGACTTCATTGCCTTGG & СТCTCCTCTCCAGTACGTCCTTCC & 171 & EU170468 \\
\hline IL-1 $\beta$ & CCACCTTTACCAGCTTCGAG & CCGTTCTTCATCCAGGTGAT & 80 & NM_204524 \\
\hline
\end{tabular}

$10 \times$ binding buffer, followed by treatment with $10 \mu \mathrm{l}$ of FITC-labeled annexinV per sample for $5 \mathrm{~min}$ at room temperature. Then, the infected cells were stained with $5 \mu \mathrm{l}$ of propidium iodide (PI) per sample for $10 \mathrm{~min}$, followed by analysis in a FC500 flow cytometer (Beckman Coulter, Brea, CA, USA). AnnexinV-positive and PI-negative cell populations in the lower right quadrant of the AnnexinV versus PI FACS plot were regarded as apoptotic cells.

\section{RNA extraction and qRT-PCR}

Total RNA of tissues were extracted with TRIzol reagent (Invitrogen, Carlsbad, CA, USA) following the manufacturer's instructions. After treatment with DNase I (Takara), $1 \mu \mathrm{g}$ of total RNA was reverse transcribed using the RevertAid First Strand cDNA synthesis kit (Takara, Dalian, China). Then, cDNA was used for real-time PCR amplification performed using the QuantiFast SYBR Green PCR kit (Qiagen) and a 7500 Fast Real-Time PCR system (Applied Biosystems, Rotkreuz, Switzerland). PCR primers used are summarized in Table 1. PCR protocol included one cycle of $95^{\circ} \mathrm{C}$ for 5 min followed by 40 cycles of $95^{\circ} \mathrm{C}$ for $15 \mathrm{~s}$ and $60^{\circ} \mathrm{C}$ for $34 \mathrm{~s}$ for amplification. Each tissue sample was tested in triplicate. Expression levels of target genes were normalized to a constitutively expressed housekeeping gene, GAPDH, and the fold change for each gene was calculated using the $2^{-\triangle A C T}$ method [45].

\section{Statistical analysis}

All data are presented as Mean $\pm S D$. Statistically significant differences were determined by a two-tailed independent Student's $t$ test using Prism 6.0 (Graph Pad Software Inc., San Diego, CA, USA) and $p<.05$ were considered statistically significant.

\section{ACKNOWLEDGMENTS AND FUNDING}

This study was supported by grants from the National Natural Science Foundation of China (No.31072139, 
No. 31372412), the Science and Technology Projects of Guangdong Province (No.2012A020800006), the Chinese Special Fund for Agro-scientific Research in the Public Interest (No.201303033) and the Doctoral Fund of Ministry of Education of China (No. 20124404110016).

\section{CONFLICTS OF INTEREST}

The authors declare that no competing interests exist.

\section{REFERENCES}

1. Alexander DJ. Newcastle disease and other avian paramyxoviruses. Rev Sci Tech. 2000; 19:443-462.

2. Steward M, Vipond IB, Millar NS, Emmerson PT. RNA editing in Newcastle disease virus. J Gen Virol. 1993; 74:2539-2547.

3. Kang Y, Xiang B, Yuan R, Zhao X, Feng M, Gao P, Li Y, Ning Z, Ren T. Phylogenetic and Pathotypic Characterization of Newcastle Disease Viruses Circulating in South China and Transmission in Different Birds. Front Microbiol. 2016; 7:119.

4. Edinger AL, Thompson CB. Death by design: apoptosis, necrosis and autophagy. Curr Opin Cell Biol. 2004; 16:663-669.

5. Fuchs Y, Steller H. Programmed cell death in animal development and disease. Cell. 2011; 147:742-758.

6. Jacobson MD, Weil M, Raff MC. Programmed cell death in animal development. Cell. 1997; 88:347-354.

7. Porter AG, Janicke RU. Emerging roles of caspase-3 in apoptosis. Cell Death Differ. 1999; 6:99-104.

8. Igney FH, Krammer PH. Death and anti-death: tumour resistance to apoptosis. Nat Rev Cancer. 2002; 2:277-288.

9. Kurokawa M, Kornbluth S. Caspases and kinases in a death grip. Cell. 2009; 138:838-854.

10. Everett H, McFadden G. Apoptosis: an innate immune response to virus infection. Trends Microbiol. 1999; 7:160-165.

11. Griffin DE, Hardwick JM. Regulators of apoptosis on the road to persistent alphavirus infection. Annu Rev Microbiol. 1997; 51:565-592.

12. Teodoro JG, Branton PE. Regulation of apoptosis by viral gene products. J Virol. 1997; 71:1739-1746.

13. Levine B, Mizushima N, Virgin HW. Autophagy in immunity and inflammation. Nature. 2011; 469:323-335.

14. Mizushima N, Yoshimori T, Levine B. Methods in mammalian autophagy research. Cell. 2010; 140:313-326.

15. Heaton NS, Randall G. Dengue virus-induced autophagy regulates lipid metabolism. Cell Host Microbe. 2010; 8:422-432.

16. Rossman JS, Lamb RA. Autophagy, apoptosis, and the influenza virus M2 protein. Cell Host Microbe. 2009; 6:299-300.
17. Blanchet FP, Moris A, Nikolic DS, Lehmann M, Cardinaud S, Stalder R, Garcia E, Dinkins C, Leuba F, Wu L, Schwartz O, Deretic V, Piguet V. Human immunodeficiency virus-1 inhibition of immunoamphisomes in dendritic cells impairs early innate and adaptive immune responses. Immunity. 2010; 32:654-669.

18. Su WC, Chao TC, Huang YL, Weng SC, Jeng KS, Lai MM. Rab5 and class III phosphoinositide 3-kinase Vps34 are involved in hepatitis C virus NS4B-induced autophagy. J Virol. 2011; 85:10561-10571.

19. Lam KM. Apoptosis in chicken embryo fibroblasts caused by Newcastle disease virus. Vet Microbiol. 1995; 47:357-363.

20. Sun Y, Yu S, Ding N, Meng C, Meng S, Zhang S, Zhan Y, Qiu X, Tan L, Chen H, Song C, Ding C. Autophagy benefits the replication of Newcastle disease virus in chicken cells and tissues. J Virol. 2014; 88:525-537.

21. Meng C, Zhou Z, Jiang K, Yu S, Jia L, Wu Y, Liu Y, Meng S, Ding C. Newcastle disease virus triggers autophagy in U251 glioma cells to enhance virus replication. Arch Virol. 2012; 157:1011-1018.

22. Meng G, Xia M, Wang D, Chen A, Wang Y, Wang H, Yu D, Wei J. Mitophagy promotes replication of oncolytic Newcastle disease virus by blocking intrinsic apoptosis in lung cancer cells. Oncotarget. 2014; 5:6365-6374. https:// doi.org/10.18632/oncotarget.2219.

23. Kang Y, Yuan R, Zhao X, Xiang B, Gao S, Gao P, Dai X, Feng M, Li Y, Xie P, Li Y, Gao X, Ren T. Transient activation of the PI3K/Akt pathway promotes Newcastle disease virus replication and enhances anti-apoptotic signaling responses. Oncotarget. 2017; 8:23551-63. https:// doi.org/10.18632/oncotarget.15796.

24. Mizushima N. Methods for monitoring autophagy. Int J Biochem Cell Biol. 2004; 36:2491-2502.

25. Klionsky DJ, Abdelmohsen $\mathrm{K}$, Abe A, Abedin MJ, Abeliovich H, Acevedo Arozena A, Adachi H, Adams CM, Adams PD, Adeli K, Adhihetty PJ, Adler SG, Agam G, et al. Guidelines for the use and interpretation of assays for monitoring autophagy (3rd edition). Autophagy. 2016; $12: 1-222$.

26. Deretic V, Saitoh T, Akira S. Autophagy in infection, inflammation and immunity. Nat Rev Immunol. 2013; 13:722-737.

27. Kang R, Zeh HJ, Lotze MT, Tang D. The Beclin 1 network regulates autophagy and apoptosis. Cell Death Differ. 2011; 18:571-580.

28. Wang J. Beclin 1 bridges autophagy, apoptosis and differentiation. Autophagy. 2008; 4:947-948.

29. Elankumaran S, Rockemann D, Samal SK. Newcastle disease virus exerts oncolysis by both intrinsic and extrinsic caspase-dependent pathways of cell death. J Virol. 2006; 80:7522-7534.

30. Dreux M, Chisari FV. Autophagy proteins promote hepatitis C virus replication. Autophagy. 2009; 5:1224-1225. 
31. Gannage M, Dormann D, Albrecht R, Dengjel J, Torossi T, Ramer PC, Lee M, Strowig T, Arrey F, Conenello G, Pypaert M, Andersen J, Garcia-Sastre A, et al. Matrix protein 2 of influenza A virus blocks autophagosome fusion with lysosomes. Cell Host Microbe. 2009; 6:367-380.

32. Zhou Z, Jiang X, Liu D, Fan Z, Hu X, Yan J, Wang M, Gao GF. Autophagy is involved in influenza A virus replication. Autophagy. 2009; 5:321-328.

33. Lee YR, Lei HY, Liu MT, Wang JR, Chen SH, JiangShieh YF, Lin YS, Yeh TM, Liu CC, Liu HS. Autophagic machinery activated by dengue virus enhances virus replication. Virology. 2008; 374:240-248.

34. Pei J, Zhao M, Ye Z, Gou H, Wang J, Yi L, Dong X, Liu W, Luo Y, Liao M, Chen J. Autophagy enhances the replication of classical swine fever virus in vitro. Autophagy. 2014; 10:93-110.

35. Li S, Zhou A, Wang J, Zhang S. Interplay of autophagy and apoptosis during PRRSV infection of Marc145 cell. Infect Genet Evol. 2016; 39:51-54.

36. Wang G, Yu Y, Tu Y, Tong J, Liu Y, Zhang C, Chang Y, Wang S, Jiang C, Zhou EM, Cai X. Highly Pathogenic Porcine Reproductive and Respiratory Syndrome Virus Infection Induced Apoptosis and Autophagy in Thymi of Infected Piglets. PLoS One. 2015; 10:e0128292.

37. Joubert PE, Werneke SW, de la Calle C, GuivelBenhassine F, Giodini A, Peduto L, Levine B, Schwartz O, Lenschow DJ, Albert ML. Chikungunya virus-induced autophagy delays caspase-dependent cell death. J Exp Med. 2012; 209:1029-1047.

38. Xi X, Zhang X, Wang B, Wang T, Wang J, Huang H, Wang J, Jin Q, Zhao Z. The interplays between autophagy and apoptosis induced by enterovirus 71. PLoS One. 2013; 8:e56966.

39. Sirois I, Groleau J, Pallet N, Brassard N, Hamelin K, Londono I, Pshezhetsky AV, Bendayan M, Hebert MJ. Caspase activation regulates the extracellular export of autophagic vacuoles. Autophagy. 2012; 8:927-937.

40. Boya P, Gonzalez-Polo RA, Casares N, Perfettini JL, Dessen P, Larochette N, Metivier D, Meley D, Souquere S, Yoshimori T, Pierron G, Codogno P, Kroemer G. Inhibition of macroautophagy triggers apoptosis. Mol Cell Biol. 2005; 25:1025-1040.

41. Deretic V, Levine B. Autophagy, immunity, and microbial adaptations. Cell Host Microbe. 2009; 5:527-549.

42. Piekarski A, Khaldi S, Greene E, Lassiter K, Mason JG, Anthony N, Bottje W, Dridi S. Tissue distribution, genderand genotype-dependent expression of autophagy-related genes in avian species. PLoS One. 2014; 9:e112449.

43. Kang Y, Feng M, Zhao X, Dai X, Xiang B, Gao P, Li Y, Ren T. Newcastle disease virus infection in chicken embryonic fibroblasts but not duck embryonic fibroblasts is associated with elevated host innate immune response. Virol J. 2016; 13:41.

44. Kang Y, Li Y, Yuan R, Feng M, Xiang B, Sun M, Li Y, Xie P, Tan Y, Ren T. Host Innate Immune Responses of Ducks Infected with Newcastle Disease Viruses of Different Pathogenicities. Front Microbiol. 2015; 6:1283.

45. Livak KJ, Schmittgen TD. Analysis of relative gene expression data using real-time quantitative PCR and the 2(-Delta Delta C(T)) Method. Methods. 2001; 25:402-408. 